\title{
CHARACTERIZATION OF THE GEOPHAGIC MATERIALS AND THEIR ASSOCIATED ROCKS AND SOILS FROM ANFOEGA, GHANA
}

\author{
J. K. Badu, P. M. Nude, D. E. Dodor, E. K. Nartey And T. A. Adjadeh*. \\ (J. K. B., D. E. D., E. K. N. \& T. A. A.: Department of Soil Science, University of Ghana, \\ Legon-Accra, Ghana; P. M. N.: Department of Earth Science, \\ University of Ghana, Legon-Accra, Ghana). \\ *Corresponding author’s email: tadjadeh@ug.edu.gh
}

\begin{abstract}
This study was conducted to examine the physico-chemical and mineralogical properties of geophagic materials and their associated rocks and soils from Anfoega, Ghana. The geophagic materials were sampled from pits $>10 \mathrm{~m}$ deep overlain by massive sandstones and shallow soils which were also sampled. The $\mathrm{pH}$ of the geophagic materials was strongly acid. The $\mathrm{pH}$ of the soils from the three sites was slightly to moderately acid, that of the fourth site was moderately acid in the surface but strongly acid in the lower layers. While the geophagic materials were enriched with clay, the soil samples contained high amounts of sand. The CEC of the geophagic materials (18.0 to $23.2 \mathrm{cmol} \mathrm{kg}^{-1}$ ) was higher than that of the soils (5.3 to $22.6 \mathrm{cmol}_{\mathrm{c}} \mathrm{kg}^{-1}$ ). Thin sections of the rocks showed high amounts of quartz and accessory feldspars and sericite. The geophagic materials contained high amounts of clay (with $>79 \% \mathrm{SiO}_{2}$ ), quartz, feldspars and sericite. X-ray diffractograms of the geophagic materials, rocks and soils were dominated by quartz, kaolinite, muscovite and feldspars. The sialic minerals in the geophagic materials (shales) were probably leached from the overlying sandstones. The mineralogy of the soils indicated that they were formed in-situ from the underlying sandstones.
\end{abstract}

Keywords: Geophagic materials, Anfoega, sandstones, soils, sialic shales.

\section{Introduction}

Geophagy, a term used to describe eartheating was reported to have been first used by Aristotle (Mahaney et al., 2000). The term is derived from two Greek words geo-(earth) and phag-(eat) (Halstead, 1968). Earth-eating has been observed throughout history in humans and animals (Krishnamani \& Mahaney, 2002) and in all cultures all over the world (Hunter, 1993; Brand et al., 2009). However, the practice is reported to be more common in children and pregnant women in tropical peasant societies than in temperate regions
(Abrahams \& Parsons, 1996; Abrahams, 2002; Hooda et al., 2004; Gonyea, 2007). Geophagy is a sub-group of pica which has been defined as ingestion of non-food substances (Moore \& Sears, 1994; Ziegler, 1997). Danford (1982), reported that Ambroise Pare' (1510 - 1590) a French barber was the first to use the term pica as a perverted craving for substances unfit to be used as food. Pica in humans has many different subgroups based on the substance that is ingested but the most reported is geophagy (deliberate eating of soil) (Wilson, 2004; Landa \& Feller, 2009). Other sub- 
groups of pica involving ingestion of starch (amylophagia), ice (pagophagia), matches (cautopyrelophagia), hair (trichophagia), ashes from cigarettes (stachtophagia), stones or rocks (lithophagia) and wood toothpicks (xylophagia), have also been reported (Wilson, 2003; Young, et al., 2008). Inadvertent consumption of earth would not be considered geophagy or pica (Abrahams, 2005).

Archeological evidence of a calcium rich clay found next to the prehistoric remains of Homo habilis at the Kalambo Falls on the border between Zambia and Tanzania suggests that geophagy predates our evolution as a species (Clark, 2001) and this remains the oldest evidence of earth-eating by humans (RootBernstein \& Root-Bernstein, 2000). Other records on geophagy date as far back as $40 \mathrm{BC}$ (Ghorbani, 2008) and the $13^{\text {th }}$ century during Greek and Roman Ages (Rose et al., 2000).

Largely, the aetiology of geophagy has long remained elusive (Laufer, 1930). Attempts by various researchers to get enough information from geophagists to ascertain what triggers the practice have generally been futile. Even in Africa, where the practice is open, geophagists are reluctant to give reasons for the habit (Vermeer, 1987) for fear of stigmatization (Abraham, 2005; Young et al., 2008). However, certain factors like the environment, belief systems and the mental state of the geophagists have been reported to influence indulgence in geophagy (Abrahams, 2005). Also, medicinal, psychological, cultural, physiological as well as nutritional reasons have been advanced to justify the practice of geophagia (Hunter \& Kleine, 1984; Vermeer, 1996; Geissler et al., 1998; Callahan, 2000; Harvey et al., 2000). Laufer (1930) had noted that preferences for types of geophagic materials are determined by colour, texture, odour and plasticity which are largely influenced by mineralogical properties of the materials.
Three major hypotheses have been postulated to explain geophagic behaviour in humans namely hunger hypothesis, micronutrient deficiency hypothesis and protection hypothesis (Wilson, 2003; Young et al., 2010). The hunger hypothesis postulates that people consume clay materials because they do not have anything else to eat (Laufer, 1930). In fact, resorting to geophagy in times of hunger is beyond hypothesis. Soil is consumed to suppress hunger or as a filler to substitute for food (Laufer, 1930; Reilly \& Henry, 2000; Woywodt \& Kiss, 2002; Wilson, 2003; Tayie, 2004). During the 2002 food shortage in Malawi, people engaged in earth eating (Abraham, 2005). The micronutrient deficiency hypothesis states that people ingest clay materials to supplement nutrients (Hunter, 1973). The protection hypothesis posits that geophagia is motivated by the desire to mitigate harmful effects of toxins, chemicals, or microbes in the body (Young et al., 2010). According to Starks \& Slabach (2012), the negatively charged clay molecules can easily bind to positively charged toxins in the stomach and oesophagus and thereby prevent the toxin from being absorbed into the bloodstream.

Literature is replete with reports on how cultures perceive and practise geophagy. For example, in the eastern part of Nigeria, clay and earthy substances are used by native doctors to cure various diseases (Izugbara \& Emmanuel, 2003). People of the Tiv tribe of Nigeria believe that craving for dirt (i.e., soil) by women is a sign of pregnancy (Starks \& Slabach, 2012). South African urban women believe that ingesting soils enhances their beauty (Woywodt \& Kiss, 2002) and in Malawi the practice is believed to confirm pregnancy (Ghorbani, 2008). In the southern parts of the United States of America, pregnant women ingest soil because they believe it can cure swollen legs, helps babies to thrive 
and grow into beautiful children (Tayie, 2004 \& Ghorbani, 2008). Furthermore, in some cultures, geophagia is more than just a craving to satisfy nutritional, medicinal or psychological needs but an identity that reaffirms bonds with mother earth (Siewe et $a l, 2000)$. For example, in Mexico, members of the Black Christ cult in the shrine of the Santiago de Esquipulas practised clay eating as a religious ritual (Hunter, et al., 1989).

In modern medicine, pharmaceutical companies have taken advantage of the binding properties of kaolin to produce kaopectate, a drug used for the treatment of diarrhoea and other digestive ailments (Starks \& Slabach, 2012) as well as treatment of some types of poisoning (Abrahams, 2005).

Geophagy has also been associated with bad health conditions since toxic elements and microbial contaminants are usually ingested along with soil. Diseases such as toxoplasmosis and parasitic worm infestation have been reported to be prevalent among geophagists (Wong et al., 1991). Other conditions such as malnutrition, oral and dental health problems, intestinal perforation and blockage have also been reported to be associated with geophagia (Tayie, 2004; Stiegler, 2005 and Gonyea, 2007).

Geophagic materials are usually soil sediments that are predominantly clay in particle size and contain at least one clay mineral (Ekosse et al., 2010; Ngole et al., 2010). The characteristics of a geophagic material when ingested would depend on its physical, chemical and mineralogical properties which to a large extent are influenced by pedogenesis (Reilly \& Henry, 2000; Ngole et al., 2010). Clay minerals are components of soils and constitute part of the geological structure of the earth (Mahaney et al., 2000). Further, they are secondary minerals derived from chemical alteration of mostly feldspars and micas (Ekosse et al., 2010) and they control most of the physical, chemical and biological properties of soils (Schulze, 2005). Geophagic clays vary from one region to another with varied mineralogical and chemical compositions (Ferrell, 2008).

In Ghana, geophagic materials are obtained mainly from Anfoega in the Volta Region (Vermeer, 1971). The materials are mined from pits enriched with weathered shales such as found in the Accraian and the Togo rocks (Vermeer, 1971). No elaborate exploration or prospecting exercise is carried out prior to mining of the material (Ekosse et al., 2010). In most cases, local miners use simple digging tools (Gosselain, 1999). Mining is solely done by men while women play active roles in processing and marketing of the materials. The miners normally do not reclaim the mined sites.

Several studies have been done on geophagia in Ghana (Woywodt \& Kiss, 2002, Tayie et al., 2013). These studies have focused mainly on reasons for the practice (Vermer, 1971; Hunter, 1973), health implications (TanoDebrah \& Bruce-Baiden, 2010), nutritional benefits (Abrahams \& Parsons, 1997; Tayie et al., 2013) and cultural or traditional beliefs associated with the practice (Vermeer \& Frate, 1979). Although the Buem rocks in which the mining sites at Anfoega are located have been reported to be predominantly composed of sandstones and shales (Kesse, 1985), there has been no reported study on the physicochemical properties and mineralogical composition of the geophagic materials. Thus, the objective of this study was to examine the physico-chemical properties and mineralogical composition of the geophagic materials from Anfoega and possible relationship with their associated rocks and soils. 


\section{Experimental}

\section{Geology of the study area}

The Anfoega area is underlain by rocks of the Buem Structural Unit (BSU) which forms the westernmost unit of the Dahomeyide orogen in Ghana (Agyei Duodu et al. 2009). The BSU has been described by many workers including Kesse (1985), Affaton (1997), Dapaah-Siakwa \& Gyau-Boakye (2009) as consisting of a thick lower sequence of clastic sediments with some carbonates and tillite units, overlain by volcanic rocks (including mafic flow units and pyroclastic rocks), serpentine and clastic rocks. According to Jones (1990) the clastic units comprise sandstones, fine-grained quartzites, siltstones and shales, with series of bedded, normally red cherts of massive appearance and brecciated jaspers associated with the volcanic rocks. The volcanic rocks constitute a unique assemblage among the monocyclic sedimentary formations of this structural unit (Nude et al., 2015). The Buem sandstones have been classified as quartz arenite and feldspathic arenite (Osae, et al. (2006). It has also been reported that the Anfoega area particularly, Wuve, Tokorme, Agata and Agatanyigbe have large deposits of kaolin (Vermeer, 1971; Ghana Statistical Service, 2010). The Bliku hills of Anfoega which span Wuve, Tokorme, Agata, Agatanyigbe and beyond is the major source of the geophagic materials in Ghana (Ghana Statistical Service, 2010). The four communities of Anfoega are jointly called Anfoega Bume.

Vegetation of the study area

The vegetation at Anfoega is a mixture of Guinea Savannah woodland and Semi- deciduous forest (Unimax Macmillan, 2001; Ghana Statistical Service, 2010). The Savannah woodland consists of grass with scattered trees like acacia (Acacia sp.), bamboo (Bambusa vulgaris) and baobab (Adansonia digitata L.). The semi-deciduous forests are found on the slopes of the Akwapim-Togo-Atakora range, including the Bliku hills, with many tree species which are also found in the high forest zones, such as Tsentsen (Antiaris toxicaria) and Odum (Milicia excelsa), and oil palm (Elaeis guineensis) (Ghana Statistical Service, 2010).

\section{Study sites}

The study sites were at Tokorme and Wuve, two communities under Anfoega Bume in the North Dayi District of the Volta Region of Ghana (Fig. 1). Four major mining sites, all located on the shoulder of the Bliku hills, were selected for the study. Three sites were located at Tokorme and one at Wuve. Their specific locations and elevations are shown in Fig. 1 and Table 1. Each study site (mined pit) and its surroundings had a shallow soil (about $60 \mathrm{~cm}$ ) at the surface underlain by a massive rock of about $10 \mathrm{~m}$ thick and a deposit of geophagic materials at the bottom (Fig. 2). The dominant soils in the area were classified as Lixisols by the Soil Research Institute (1999).

\section{Sample collection and storage}

At each of the four sites, geophagic materials were sampled from deposits located at depths more than $10 \mathrm{~m}$ in pits dug by miners. Samples of the overlying rocks and soils were also taken. The soils were sampled from depths of $0-20,20-30,30-40,40-50$ and $50-60 \mathrm{~cm}$. Core samples were also taken within the depth of $0-40 \mathrm{~cm}$ for bulk density determination. 


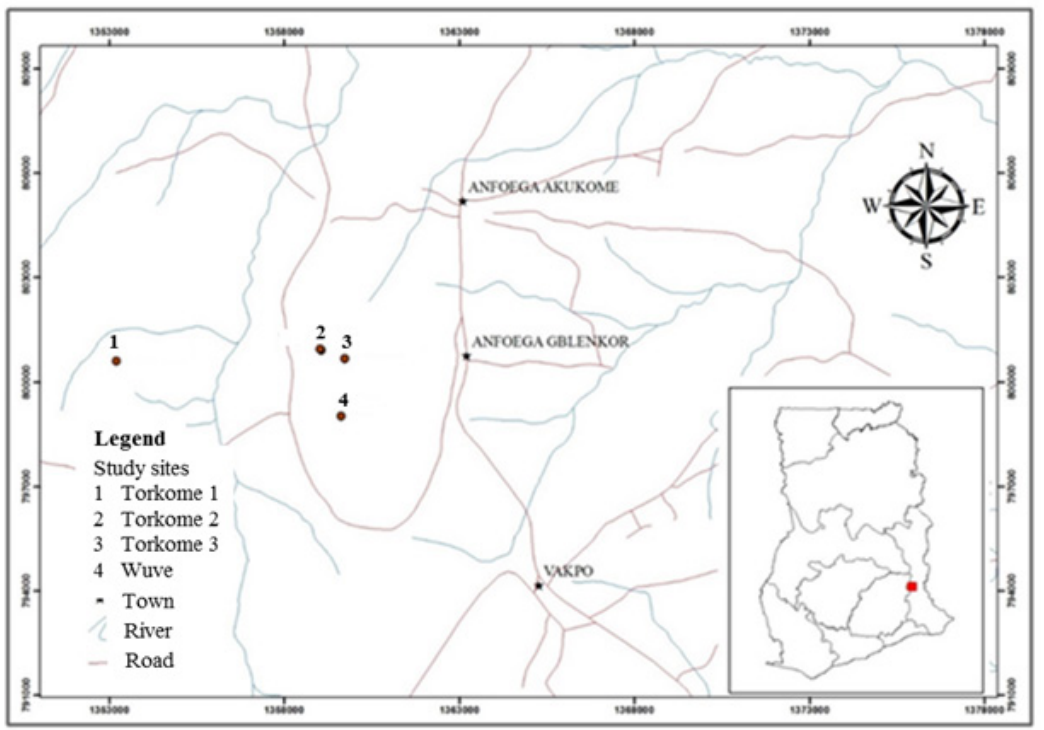

Fig. 1: Location of study sites.

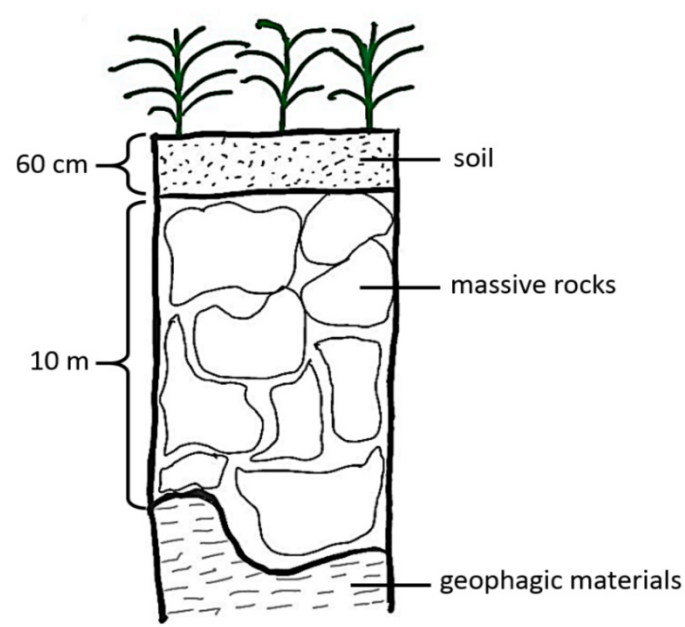

Fig. 2: A sketch of vertical cross-section of a pit indicating the positions of soil, rocks and the geophagic materials.

\section{Morphological properties}

The Revised Standard Soil Colour Charts (Oyama \& Takehara, 1970) were used to determine the colour of the soils under fieldmoist conditions and after the samples had been air-dried in the laboratory. The other morphological properties namely structure, consistence and root distribution were determined according to the Guidelines for Soil Description (FAO, 2006). All samples (soils, geophagic materials and rocks) were put into labelled polythene bags and transported to the laboratory of the Department of Soil Science, University of Ghana. At the laboratory, the geophagic materials and soil samples were air-dried and then gently disaggregated using an agate mortar and pestle. The disaggregated samples were then passed through a 2.0 $\mathrm{mm}$ mesh sieve and re-bagged for physical, chemical, and mineralogical analyses. The rock samples were subjected to petrographic and $\mathrm{x}$-ray examination. 
Physical properties

Bulk density of the soils

Undisturbed core samples were taken at field moist state with cylindrical metal core samplers which were $5 \mathrm{~cm}$ in both diameter and height. The samples were oven-dried at $105^{\circ} \mathrm{C}$ for 24 hours after which their bulk density was determined according to the method described by Blake (1965).

\section{Particle size distribution}

The sand $(2.00-0.05 \mathrm{~mm})$, silt $(0.05-0.002$ $\mathrm{mm})$ and clay $(<0.002 \mathrm{~mm})$ fractions of the soils were determined using the modified Bouyoucos hydrometer method (Day, 1965) after the samples had been treated with $30 \% \mathrm{H}_{2} \mathrm{O}_{2}$ and dispersed with sodium hexametaphosphate. The textural class of the soils was determined using the USDA textural triangle.

\section{Chemical properties}

Soil reaction, $\mathrm{pH}\left(\mathrm{H}_{2} \mathrm{O}\right.$ and $\left.\mathrm{CaCl}_{2}\right)$ of the geophagic materials and soils

The $\mathrm{pH}\left(\mathrm{H}_{2} \mathrm{O}\right)$ and $\mathrm{pH}\left(\mathrm{CaCl}_{2}\right)$ of the geophagic materials and soil samples were determined with a glass electrode ( $\mathrm{pH}$ meter, PL 700PV) in a 1:2 soil-water / $0.01 \mathrm{M} \mathrm{CaCl}_{2}$ after stirring and allowing the samples to stand for 1 hour.

\section{Electrical conductivity}

Electrical conductivity of the geophagic materials and soils samples was determined with a glass conductivity electrode (EC meter, PL700AL) in a 1:2 soil-de-ionized water after stirring for about 1 hour and allowed to stand for $30 \mathrm{~min}$.

\section{Organic carbon}

Organic carbon content of the geophagic materials and soil samples was determined according to the method described by Walkley \& Black (1934).

\section{Total nitrogen}

The total nitrogen content of the geophagic materials and the soil samples was determined using the Kjedahl digestion method (Hesse, 1971).

Exchangeable bases and cation exchange capacity (CEC)

The exchangeable bases and the CEC of the geophagic materials and the soils were determined using ammonium acetate $(1 \mathrm{M}, \mathrm{pH}$ 7.0). The concentrations of the exchangeable bases in the ammonium acetate percolate were determined with the AAnalyst 800 Perkin Elmer atomic absorption spectrophotometer. For CEC, after percolation with ammonium acetate, the samples were washed free of excess salt using four $25 \mathrm{ml}$ portions of methanol. The ammonium saturated samples were then washed with four $25 \mathrm{ml}$ portions of acidified $\mathrm{KCl}(1 \mathrm{~L}$ of $1 \mathrm{M} \mathrm{KCl}+1 \mathrm{ml}$ of 12 $\mathrm{M} \mathrm{HCl}$ ). To $5 \mathrm{ml}$ of the leachate, $5 \mathrm{ml} 40 \%$ $\mathrm{NaOH}$ was added and distilled using the Kjedahl distillation unit. The distillates were collected in $2 \%$ boric acid, titrated with 0.01 $\mathrm{M} \mathrm{HCl}$ until there was a colour change from green to a purple end point. The CEC was calculated from the number of moles of the $\mathrm{HCl}$ consumed in the back titration in $\mathrm{cmol}_{\mathrm{c}}$ $\mathrm{kg}^{-1}$.

\section{Determination of total phosphorus}

A $2.0 \mathrm{~g}$ (screened through $0.5 \mathrm{~mm}$ sieve) of each sample was put into a $250 \mathrm{ml}$ Erlenmeyer flask. Then $10 \mathrm{ml}$ of concentrated $\mathrm{HNO}_{3}$ and $15 \mathrm{ml}$ of $60 \% \mathrm{HClO}_{4}$ were added to each sample and the mixture digested. Thereafter, a $5.0 \mathrm{ml}$ aliquot of the digest was pipetted and mixed thoroughly and made to stand until blue colour developed. The total P contents were determined after reading absorbance at a wavelength of $712 \mathrm{~nm}$. 


\section{Available phosphorus}

The available $\mathrm{P}$ content of the geophagic materials and soil samples was determined following the method of Olsen et al. (1954), for samples with alkaline $\mathrm{pH}$ and the Bray and Kurtz (1945) method for samples with acidic $\mathrm{pH}$.

\section{Mineralogical properties}

Thin section preparation and petrographic examination

Thin sections of the rock samples and geophagic materials were prepared in the workshop of the Department of Earth Science, University of Ghana. The modal compositions of the samples were determined using the polarizing microscope.

\section{$X$-ray diffraction}

Clay samples from the geophagic materials and the soil samples and powdered rock samples were treated with dithionite-citratebicarbonate (Mehra \& Jackson, 1960) and mounted on glass slides after K-saturation at room temperature (air-dried). The air-dried (K-25) samples (parallel-oriented) were subjected to $\mathrm{x}$-ray diffraction. Then, the clay samples from the geophagic materials and soil samples were heated to $350^{\circ} \mathrm{C}(\mathrm{K}-350)$ and then $550^{\circ} \mathrm{C}(\mathrm{K}-550)$ and subjected to further $\mathrm{x}$-ray diffraction. The diffraction was done with a PANanalytical Empyrean X-ray powder diffractometer using a Ni-filtered $\mathrm{CuK} \alpha$ radiation generated at $45 \mathrm{kV}$ and $40 \mathrm{~mA}$.

\section{Major elemental composition of geophagic} materials

The elemental composition of the geophagic materials was determined with Orbis MicroXRF Analyzer (EDAX) at the Central Laboratory, University of Alicante, Spain. Three spots per sample were scanned under vacuum at $\mathrm{kV} 20$, Rh tube $300 \mathrm{um}-$ Spot.

\section{Results}

Morphological and physical properties of the soils and geophagic materials

The morphological and physical properties of the soils and geophagic materials are presented in Table 1. Under moist condition, the colour of the soil at Tokorme 1 ranged from brownish black (10YR3/2) in the surface layer to dull reddish brown (5YR5/4) in the bottom layer. At Tokorme 2, the colour (moist) of the soil ranged from brown $(7.5 \mathrm{YR} 4 / 4)$ in the surface layer to bright reddish brown (5YR5/6) in the bottom layer. At Tokorme 3, the colour (moist) of the soil ranged from brown (7.5YR4/4) in the surface layer to bright reddish brown (5YR5/6) in the bottom layer. At Wuve, the colour (moist) of the soil ranged from dark reddish brown (5YR3/2) in the surface layer to dull orange $(2.5 \mathrm{YR} 6 / 4)$ in the bottom layer. Under dry condition, the colour of the soil at Tokorme 1 ranged from greyish brown (7.5YR4/2) in the surface layer to dull orange (5YR7/3) in the bottom layer. At Tokorme 2, the colour (dry) of the soil ranged from dull orange $(7.5 \mathrm{YR} 6 / 4)$ in surface layer to dull orange $(7.5 \mathrm{YR} 6 / 4)$ in the bottom layer. At Tokorme 3, the dry soil colour ranged from dull reddish brown $(5 \mathrm{YR} 5 / 3)$ in the surface layer to orange (5YR7/6) in the bottom layer and at Wuve from dull orange (5YR6/3) in the surface layer to dull orange (5YR7/4) in the bottom layer.

The soils from the four sites were well drained. The soils from Tokorme 1 had granular to subangular blocky structure in the surface and subsurface layers but changed to granular in the bottom layers. The soil from Tokorme 2 had a granular to subangular blocky structure in the surface layer but changed to subangular blocky in the subsurface and bottom layers. The soils from Tokorme 3 and 
Wuve had granular structure in the surface layers but changed to subangular blocky in the subsurface and bottom layers. The soil from Tokorme 1 was generally non-sticky, friable and slightly hard in consistence under wet, moist and dry conditions respectively. The consistence of the soil from Tokorme 2 was sticky (wet), firm (moist) and very hard (dry). The Tokorme 3 soil was non sticky (wet), friable (moist) and slightly hard (dry) in consistence. The consistence of the soil from Wuve, was slightly sticky (wet), friable (moist) and hard (dry). The sizes and quantity of roots the soils contained reduced with soil depth.

The sand content of the soil from Tokorme 1 ranged from 64.7 to $66.7 \%$ and the amounts decreased slightly with depth. The silt content of Tokorme 1 ranged from 7.6 to $10.3 \%$ and the clay content from 23.0 to $27.7 \%$. In Tokorme 2, the amount of sand in the soil ranged from 33.2 to $51.2 \%$, the silt content ranged from 15.2 to $17.2 \%$ and the clay content from 33.6 to $49.6 \%$. The sand content of the soil from Tokorme 3 ranged from 25.5 to $57.2 \%$, the silt content ranged from 7.6 to $12.7 \%$ and the clay content from 34.1 to $61.5 \%$. The sand content of the soil from Wuve ranged from 64.3 to $69.5 \%$, the silt content from 10.1 to $10.6 \%$ and the clay content from 20.1 to $25.5 \%$. The clay content of the geophagic materials was $51.4 \%$ in the sample from Tokorme 1, 63.5\% in Tokorme 2, $68.8 \%$ in Tokorme 3 and $66.8 \%$ from Wuve. The silt fraction of the geophagic materials ranged from $28.66 \%$ to $45.71 \%$ while their sand fraction was less than $5 \%$. The clay fraction clearly dominated in the geophagic materials.

The texture of the soils from Tokorme 1 and Wuve was sandy clay loam throughout their profiles. The texture of the soil from Tokorme 2 was clay in the surface and subsurface layers but changed to sandy clay loam and then sandy clay in the bottom layers. In Tokorme 3, the texture of the soils was clay in the surface and subsurface layers but changed to sandy clay loam in the bottom layer. For the geophagic materials, apart from Tokorme 1 which had silty clay texture, the three other sites had clay texture.

The bulk density (BD) of the $0-20,20-30$ and $30-40 \mathrm{~cm}$ layers of the soil from Tokorme 1 ranged from 0.83 to $1.09 \mathrm{Mg} \mathrm{m}^{-3}$. The $\mathrm{BD}$ of the three top layers of the soil from Tokorme 2 ranged from 1.29 to $1.45 \mathrm{Mg} \mathrm{m}^{-3}$ while that of Tokorme 3 and Wuve ranged from 0.98 to 1.10 $\mathrm{Mg} \mathrm{m}^{-3}$ and 1.11 to $1.51 \mathrm{Mg} \mathrm{m}^{-3}$ respectively. The BD of the soils generally tended to increase with depth. 
TABLE 1

Morphological and selected physical properties of the soils and geophagic materials.

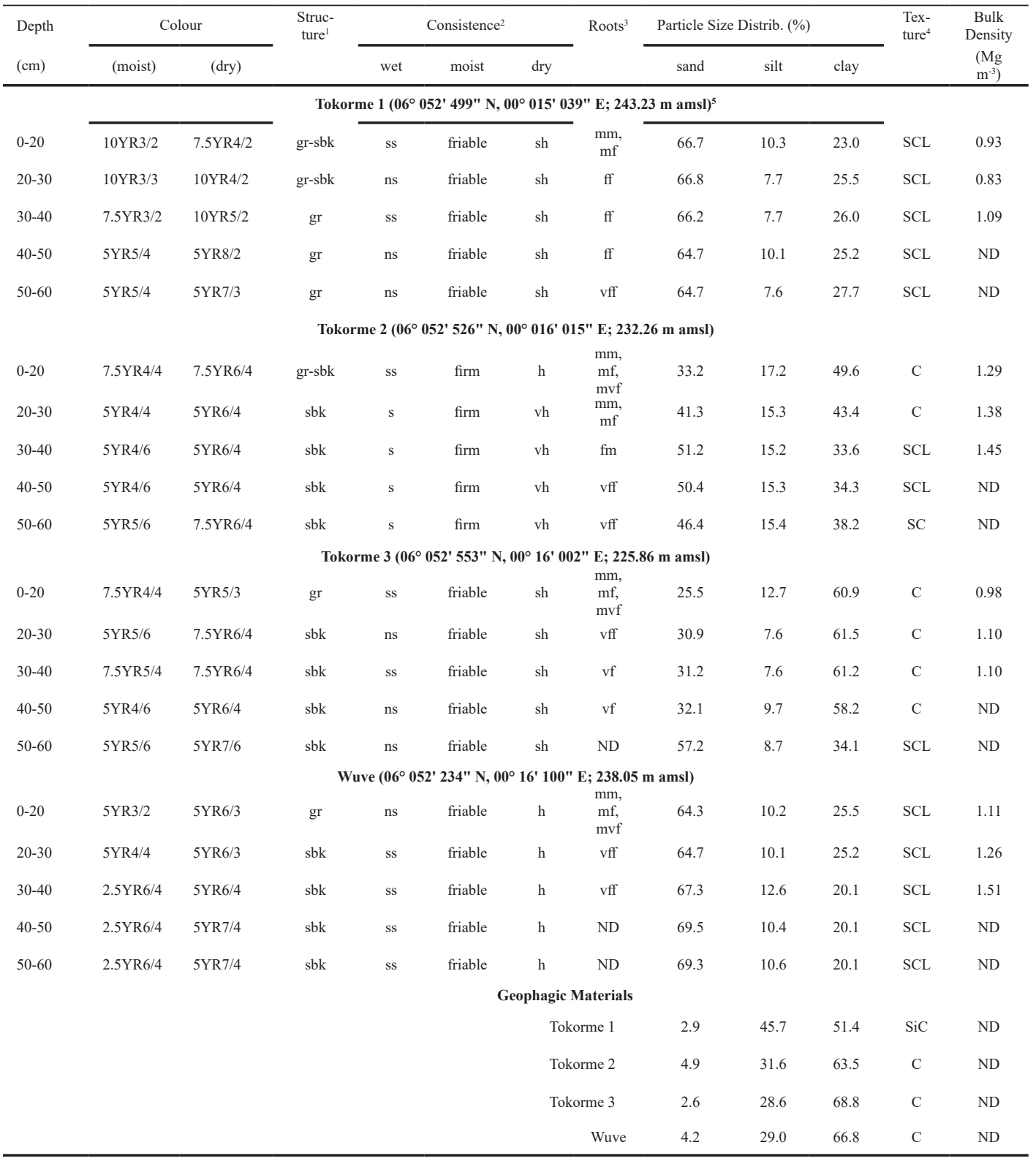

${ }^{1}$ gr, granular; sbk, subangular blocky. ${ }^{2}$ s, sticky; ss, sligtly sticky; ns, non-sticky; sh, slightly hard; h, hard; vh, very hard. ${ }^{3} \mathrm{~mm}$, many medium;

mf, many fine; mvf, many very fine; vff, very few fine; ND, not determined. ${ }^{4} \mathrm{SCL}$, sandy clay loam; C, clay; $\mathrm{SC}$, sandy clay; $\mathrm{SiC}$, silty clay, ${ }^{5} \mathrm{~m}$ amsl $=$ metres above mean sea level. 
Chemical properties of the soils and geophagic materials

The chemical properties of the soils and the geophagic materials are shown in Table 2. The soil from Tokorme 1 had neutral to slightly alkaline $\mathrm{pH}\left(\mathrm{H}_{2} \mathrm{O}\right)$ which ranged from 7.06 to 7.20. The soil from Tokorme 2 was slightly acid (pH 6.48) in the surface layer but strongly acid in the subsurface to bottom layers $(\mathrm{pH}$ 4.28 to 4.97). The $\mathrm{pH}\left(\mathrm{H}_{2} \mathrm{O}\right)$ of the soil from Tokorme 3 was slightly acid $(\mathrm{pH} 6.22$ to 6.62 ) in the surface and subsurface layers but strongly acid ( $\mathrm{pH} 4.67)$ in the bottom layer. The $\mathrm{pH}\left(\mathrm{H}_{2} \mathrm{O}\right)$ of the Wuve soil was slightly acid (pH 6.48 - 6.71) in the surface to subsurface layers and moderately acid $(\mathrm{pH}$ 6.05) in the bottom layer. The $\mathrm{pH}\left(\mathrm{H}_{2} \mathrm{O}\right)$ of the soils tended to decrease with depth. The $\mathrm{pH}\left(\mathrm{H}_{2} \mathrm{O}\right)$ of the geophagic materials was strongly acidic $(\mathrm{pH}$ 3.58 to 4.70$)$. The $\mathrm{pH}\left(\mathrm{CaCl}_{2}\right)$ of the soil from Tokorme 1 was moderately acid which ranged from $\mathrm{pH} 5.94$ to 6.22 . The $\mathrm{pH}\left(\mathrm{CaCl}_{2}\right)$ of the soil from Tokorme 2 was moderately acid in the surface layer ( $\mathrm{pH}$ 5.12) but strongly acid in the subsurface to bottom layers $(\mathrm{pH}$ 3.52 to 3.64). The soil from Tokorme 3 was moderately to slightly acid ( $\mathrm{pH}-\mathrm{CaCl}_{2}: 5.42$ to 6.39 ) in the surface to the subsurface layers but strongly acid in the bottom layers ( $\mathrm{pH} 4.61$ to 4.93). The $\mathrm{pH}\left(\mathrm{CaCl}_{2}\right)$ of the Wuve soil was moderately acid throughout the profile $(\mathrm{pH}$ 5.53-6.10). Apart from Wuve, the $\mathrm{pH}\left(\mathrm{CaCl}_{2}\right)$ of the soils tended to decrease with depth. The $\mathrm{pH}\left(\mathrm{CaCl}_{2}\right)$ of the geophagic materials was strongly acid ( $\mathrm{pH} 3.34$ to 3.60 ).

Generally, the electrical conductivity (EC) of the soils decreased with depth and the values ranged from 0.07 to $0.16 \mathrm{dS} \mathrm{m}^{-1}$ (Tokorme 1), 0.07 to $0.12 \mathrm{dS} \mathrm{m}^{-1}$ in Tokorme 2, 0.07 to $0.15 \mathrm{dS} \mathrm{m}^{-1}$ in Tokorme 3 and 0.05 to $0.13 \mathrm{dS} \mathrm{m}^{-1}$ in Wuve. The EC of the geophagic materials was about two to four folds higher than that of the soils. It ranged from $0.12 \mathrm{dS}$ $\mathrm{m}^{-1}$ in Wuve to $0.23 \mathrm{dS} \mathrm{m}^{-1}$ in Tokorme 3. All the soils and the geophagic materials were non-saline (Schoeneberger et al., 2012).

The total nitrogen contents of the soils and their associated geophagic materials were very low. However, the surface and subsurface layers of the soils from Tokorme 1 and Tokorme 2 contained relatively higher amounts of total $\mathrm{N}$. In all the soils, total $\mathrm{N}$ content generally decreased with depth. Apart from Tokorme 3, the surface layers of the soils had higher amounts of total $\mathrm{N}$ than their associated geophagic materials.

The soil from Tokorme 3 had the lowest amount of organic carbon especially in the surface $(0-20 \mathrm{~cm})$ layer $(0.51 \%)$. The organic carbon content of the surface layers of the other soils was moderately high, ranging from $1.80 \%$ in Tokorme 2 to $3.37 \%$ in Tokorme 1. The $20-30 \mathrm{~cm}$ and $30-40 \mathrm{~cm}$ layers of the soil from Tokorme 1 contained $>1.0 \%$ organic carbon. All the soils showed sharp decreases in organic carbon content from the surface layers to the subsurface layers. The geophagic materials contained much lower amounts of organic carbon which ranged from 0.07 to $0.10 \%$.

The available $\mathrm{P}$ content of the soils was low $\left(<10.0 \mathrm{mg} \mathrm{kg}^{-1}\right)$ and tended to decrease with depth. The geophagic materials also contained small amounts of available P (5.36 to 11.52 $\mathrm{mg} \mathrm{kg}{ }^{-1}$ ) which were generally comparable to the levels in the soils, especially in the surface and subsurface layers. The geophagic material from Tokorme 1 contained the highest amount of available $\mathrm{P}\left(11.52 \mathrm{mg} \mathrm{kg}^{-1}\right)$ compared to the levels in the other geophagic materials and the soils. The total $\mathrm{P}$ content of the soils was very low $\left(<50.0 \mathrm{mg} \mathrm{kg}^{-1}\right)$. The geophagic materials also contained very low amounts of total $\mathrm{P}(<$ $70.0 \mathrm{mg} \mathrm{kg}{ }^{-1}$ ) but the levels were relatively higher than those found in the soils. The geophagic material from Tokorme 1 contained 
the highest amount of total P (67.90\%) just as it also had the highest amount of available P.

The soils contained low to moderate amounts of exchangeable $\mathrm{Ca}\left(0.6\right.$ to $8.3 \mathrm{cmol}_{\mathrm{c}}$ $\mathrm{kg}^{-1}$ ) which tended to reduce with depth. The soil from Tokorme 3 had the smallest amount of exchangeable $\mathrm{Ca}$. The four soils also contained low amounts of exchangeable $\mathrm{Mg}$ $\left(0.7-1.9 \mathrm{cmol}_{\mathrm{c}} \mathrm{kg}^{-1}\right), \mathrm{K}\left(0.3-1.1 \mathrm{cmol}_{\mathrm{c}} \mathrm{kg}^{-1}\right)$ and very low $\mathrm{Na}\left(0.00-0.04 \mathrm{cmol}_{\mathrm{c}} \mathrm{kg}^{-1}\right)$. The geophagic materials from the four sites also had low levels of exchangeable bases. Whereas the exchangeable $\mathrm{Ca}$ and $\mathrm{Mg}$ contents of the soils were higher than those of the geophagic materials, the levels of $\mathrm{K}$ and $\mathrm{Na}$ in the soils were comparable to those in the geophagic materials. The CEC of the soils ranged from 5.29 to $22.56 \mathrm{cmol}_{\mathrm{c}} \mathrm{kg}^{-1}$. Generally, the soil from Wuve had the lowest CEC. The CEC levels of the geophagic materials were generally higher (18.00 to $23.18 \mathrm{cmol}_{\mathrm{c}} \mathrm{kg}^{-1}$ ) than those of the soil samples.
Petrographic characteristics of the rocks and geophagic materials

The rock sample (i.e., chip sample) from Tokorme 1 was grey, but reddish-brown on the weathered surface and composed of clasts of fine to medium grained feldspar, quartz and rock fragments. The samples from Tokorme 2 and Torkorme 3 were grey, thinly bedded, medium to coarse grained and gritty. Photomicrographs of the rock samples from the study sites are shown in Figs. 3 (a-d). Microscopically, the rocks from the three Tokorme sites were poorly sorted and composed dominantly of sub-angular to sub-rounded quartz, minor feldspar, sericite and rock fragments set in iron oxide matrix. The quartz grains were deformed while the feldspars were mostly altered into sericite but the pseudomorphs were preserved. The rock sample from Wuve was grey but reddish-brown on weathered surface. This rock was massive, gritty and friable and composed of grains of fine to medium grained clasts of feldspar, quartz and fragments of other clastic materials. Overall, the texture and mineralogy of the Wuve sample was similar to the Tokorme samples (Fig. 3d). 
TABLE 2

Chemical properties of the soils and geophagic materials

\begin{tabular}{|c|c|c|c|c|c|c|c|c|c|c|c|c|}
\hline \multirow{2}{*}{$\begin{array}{l}\text { Depth } \\
(\mathrm{cm})\end{array}$} & \multicolumn{2}{|c|}{$\mathrm{pH}$} & \multirow{2}{*}{$\begin{array}{c}\text { E.C. } \\
\left.(\mathrm{dS} \mathrm{m})^{-1}\right)\end{array}$} & \multirow{2}{*}{$\begin{array}{c}\text { Total } \\
\mathrm{N}\end{array}$} & \multirow{2}{*}{ O.C. } & \multirow{2}{*}{\multicolumn{2}{|c|}{$\begin{array}{l}\text { Avail. P Total P } \\
\left(\mathrm{mg} \mathrm{kg}^{-1}\right)\end{array}$}} & \multirow[b]{2}{*}{$\mathrm{Ca}$} & \multicolumn{3}{|c|}{ Exch. Bases $\left(\mathrm{cmol}_{\mathrm{c}} \mathrm{kg}^{-1}\right)$} & \multirow{2}{*}{$\begin{array}{l}\mathrm{CEC} \\
\left.\mathrm{kg}^{-1}\right)\end{array}$} \\
\hline & $\left(\mathrm{H}_{2} \mathrm{O}\right)$ & $\left(\mathrm{CaCl}_{2)}\right.$ & & & & & & & $\mathrm{Mg}$ & $\mathrm{K}$ & $\mathrm{Na}$ & \\
\hline \multicolumn{13}{|c|}{ Tokorme 1} \\
\hline $0-20$ & 7.20 & 6.22 & 0.16 & 0.44 & 3.37 & 7.06 & 31.30 & 8.3 & 1.7 & 0.5 & 0.03 & 13.79 \\
\hline $20-30$ & 7.16 & 6.15 & 0.14 & 0.39 & 1.95 & 3.50 & 31.80 & 5.5 & 1.5 & 0.5 & 0.03 & 19.44 \\
\hline $30-40$ & 7.06 & 6.04 & 0.10 & 0.37 & 1.05 & 6.20 & 28.35 & 2.9 & 1.6 & 0.4 & 0.02 & 10.69 \\
\hline $40-50$ & 7.12 & 6.00 & 0.07 & 0.32 & 0.63 & 3.68 & 48.15 & 1.2 & 1.2 & 0.2 & 0.00 & 10.28 \\
\hline $50-60$ & 7.07 & 5.96 & 0.07 & 0.23 & 0.59 & 5.10 & 50.80 & 1.7 & 1.3 & 0.2 & 0.01 & 8.89 \\
\hline \multicolumn{13}{|c|}{ Tokorme 2} \\
\hline $0-20$ & 6.48 & 5.12 & 0.12 & 0.42 & 1.80 & 8.48 & 48.55 & 2.4 & 1.9 & 0.7 & 0.01 & 17.17 \\
\hline $20-30$ & 4.97 & 3.64 & 0.07 & 0.33 & 0.44 & 9.62 & 41.40 & 4.7 & 1.3 & 0.3 & 0.01 & 12.57 \\
\hline $30-40$ & 4.95 & 3.62 & 0.07 & 0.27 & 0.59 & 6.00 & 43.05 & 5.6 & 1.8 & 0.5 & 0.02 & 16.88 \\
\hline $40-50$ & 4.90 & 3.52 & 0.07 & 0.12 & 0.33 & 3.98 & 46.85 & 4.3 & 1.8 & 0.4 & 0.02 & 16.42 \\
\hline $50-60$ & 4.28 & 3.60 & 0.09 & 0.14 & 0.78 & 5.10 & 48.60 & 0.7 & 1.9 & 0.4 & 0.01 & 13.04 \\
\hline \multicolumn{13}{|c|}{ Tokorme 3} \\
\hline $0-20$ & 6.62 & 6.39 & 0.15 & 0.18 & 0.51 & 9.26 & 43.25 & 2.6 & 1.6 & 1.1 & 0.01 & 15.81 \\
\hline $20-30$ & 6.58 & 5.66 & 0.08 & 0.09 & 0.28 & 7.38 & 36.35 & 0.7 & 1.5 & 0.9 & 0.01 & 11.37 \\
\hline $30-40$ & 6.33 & 5.42 & 0.09 & 0.10 & 0.45 & 4.42 & 31.85 & 0.6 & 1.6 & 1.1 & 0.00 & 13.80 \\
\hline $40-50$ & 6.22 & 4.93 & 0.07 & 0.09 & 0.27 & 4.52 & 31.25 & 0.6 & 1.7 & 1.3 & 0.01 & 13.46 \\
\hline $50-60$ & 4.67 & 4.61 & 0.08 & 0.08 & 0.29 & 2.60 & 36.95 & 0.8 & 1.6 & 1.1 & 0.00 & 22.56 \\
\hline \multicolumn{13}{|c|}{ Wuve } \\
\hline $0-20$ & 6.71 & 6.10 & 0.13 & 0.26 & 1.97 & 7.34 & 40.40 & 4.7 & 1.8 & 0.7 & 0.03 & 14.94 \\
\hline $20-30$ & 6.55 & 5.53 & 0.07 & 0.11 & 0.51 & 6.12 & 22.55 & 0.8 & 1.1 & 0.4 & 0.01 & 10.85 \\
\hline $30-40$ & 6.48 & 5.62 & 0.06 & 0.07 & 0.16 & 3.12 & 23.25 & 6.0 & 0.9 & 0.3 & 0.01 & 6.08 \\
\hline $40-50$ & 6.52 & 5.57 & 0.05 & 0.04 & 0.16 & 2.96 & 18.20 & 2.2 & 0.7 & 0.3 & 0.03 & 5.29 \\
\hline $50-60$ & 6.05 & 5.69 & 0.05 & 0.05 & 0.20 & 3.84 & 23.55 & 0.6 & 1.1 & 0.3 & 0.01 & 6.59 \\
\hline \multicolumn{13}{|c|}{ Geophagic Materials } \\
\hline Tokorme 1 & 3.58 & 3.34 & 0.60 & 0.23 & 0.07 & 11.52 & 67.90 & 0.2 & 0.2 & 1.2 & 0.03 & 20.19 \\
\hline Tokorme 2 & 4.27 & 3.57 & 0.22 & 0.06 & 0.08 & 5.36 & 46.85 & 0.5 & 1.7 & 0.5 & 0.04 & 23.18 \\
\hline Tokorme 3 & 4.28 & 3.48 & 0.20 & 0.23 & 0.10 & 5.82 & 60.50 & 0.4 & 0.7 & 0.4 & 0.02 & 18.00 \\
\hline Wuve & 4.70 & 3.60 & 0.12 & 0.20 & 0.07 & 6.00 & 51.35 & 0.9 & 1.1 & 0.4 & 0.02 & 21.92 \\
\hline
\end{tabular}


The microscopic characteristics of the geophagic materials from Tokorme 1 and Tokorme 2 are shown in Fig. 4 (a \& b). On outcrop scale, the geophagic materials from both locations were purple-grey, slightly weathered, fine to medium grained and friable. They were composed of sericitized feldspar, quartz and clay minerals, and exhibit thin parallel laminations with some being crosslaminations and with joints. Quartz occurred as clasts of silty-sand-size particles in finegrained clayey mineral matrix composed of mainly fine flakes of sericite.

\section{X-Ray diffractograms of rock samples, geophagic materials and soils}

The x-ray diffractograms of the rocks, geophagic materials and soils from the study sites are shown in Figs. 5, 6 and 7, respectively. The dominant minerals identified in the diffractograms of all the rock samples

a

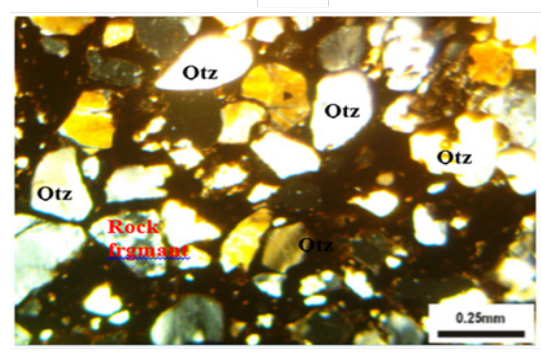

C

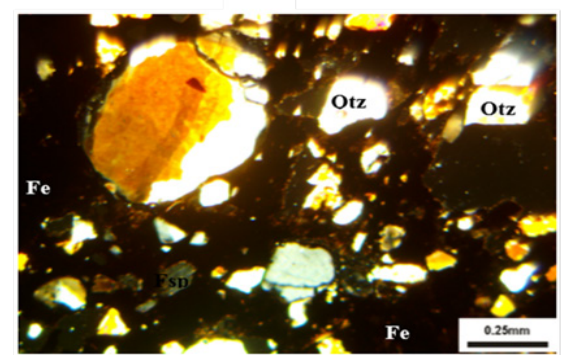

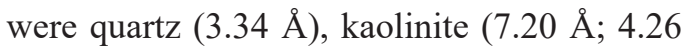
$\AA ; 2.45 \AA)$, mica $(10.02 \AA ; 1.65 \AA)$, and feldspar (4.98 $\AA$; $2.56 \AA$; $1.50 \AA$ ) (Fig. 5). The $\mathrm{x}$-ray diffractograms of the geophagic materials show that quartz $(3.34 \AA)$ as the dominant mineral in all the samples (Fig. 6). Kaolinite $\left(7.23 \AA\right.$ and collapse at $550{ }^{\circ} \mathrm{C} ; 4.26$ $\AA$; $3.52 \AA ; 2.45 \AA$ ) was also detected in all the geophagic materials. Other minerals present include feldspar (3.15 $\AA)$, mica (10.05 $\AA$ ) and muscovite (4.98 $\AA ; 4.50 \AA ; 2.57 \AA)$. The x-ray diffractograms of the clay fraction of the soils show quartz (3.35 $\AA)$ as the dominant mineral in all the samples (Fig. 7). Kaolinite was also present in all the soil samples (7.21 $\AA$ and collapse at $550{ }^{\circ} \mathrm{C} ; 3.58 \AA$ ). Other minerals present in the soils include feldspar (3.15 $\AA$ ), mica $(10.04 \AA ; 1.99 \AA)$, muscovite (5.01 $\AA$; $4.70 \AA ; 2.57 \AA)$ and montmorillonite (15.43 $\AA)$.

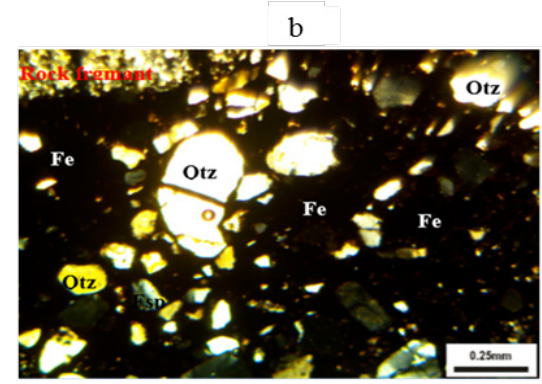

d

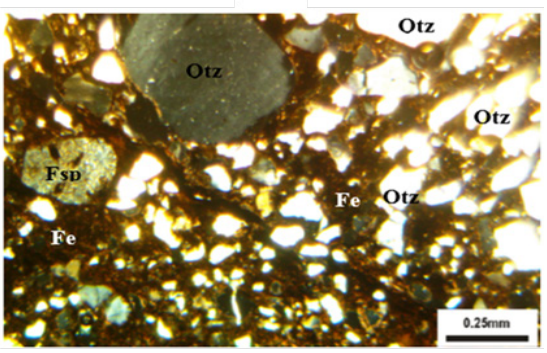

Fig. 3: A thin section of sandstones from (a) Tokorme 1, (b) Tokorme 2, (c) Tokorme 3 and (d) Wuve. 
a

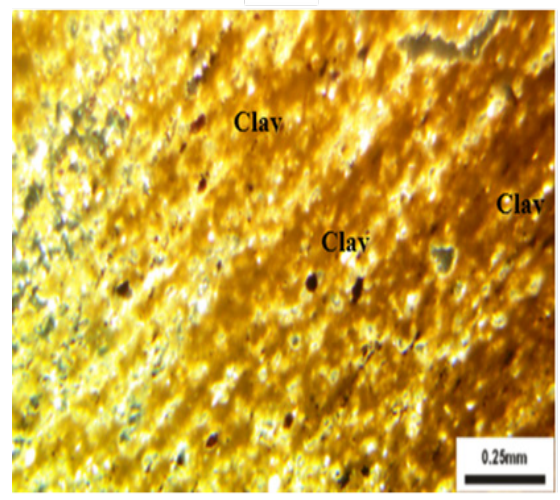

$\mathrm{b}$

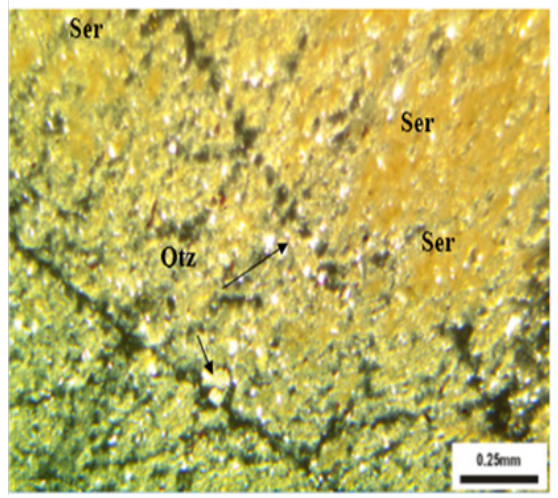

Fig. 4: Thin lamination of the geophagic materials from (a) Tokorme 1 and (b) Tokorme 2.
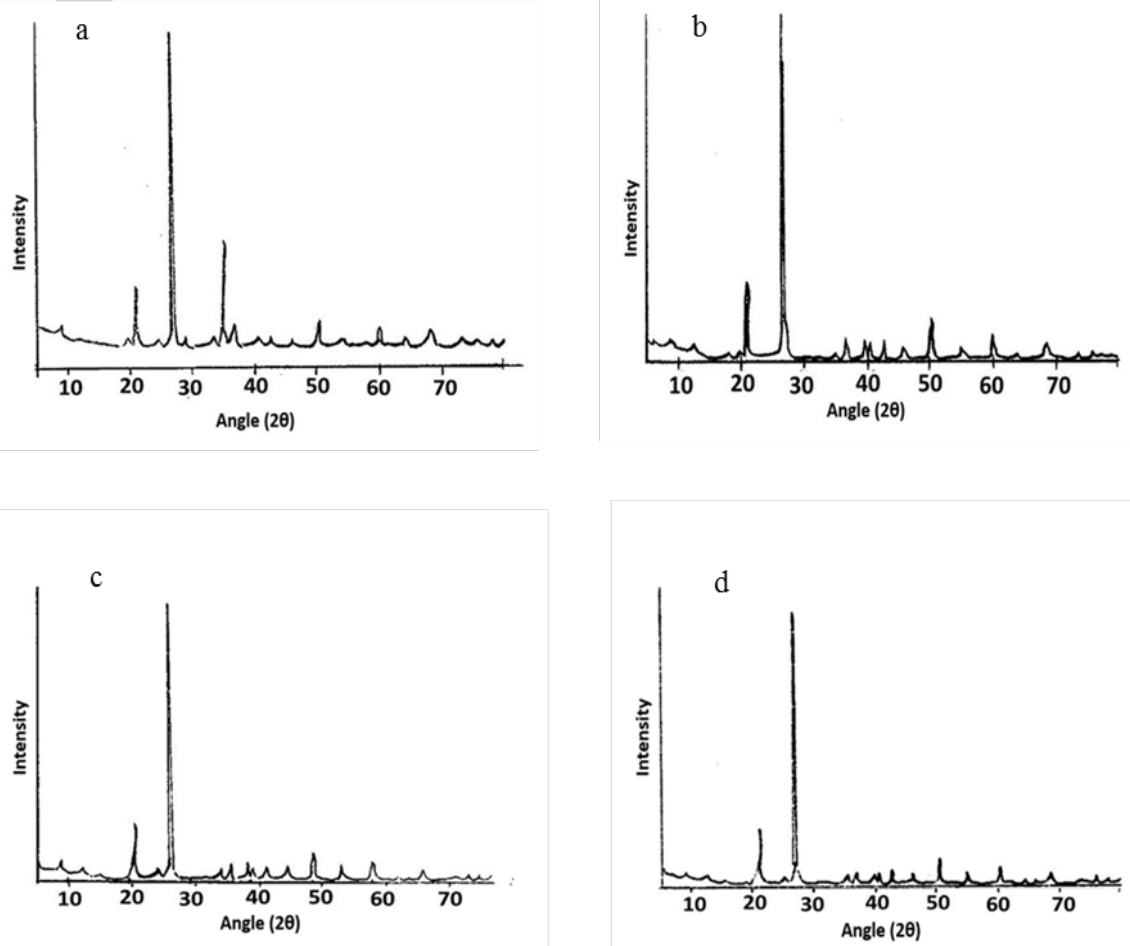

Fig. 5: X-ray diffractograms of rock samples from (a) Tokorme 1, (b) Tokorme 2 (c) Torkorme 3 (d) Wuve. 

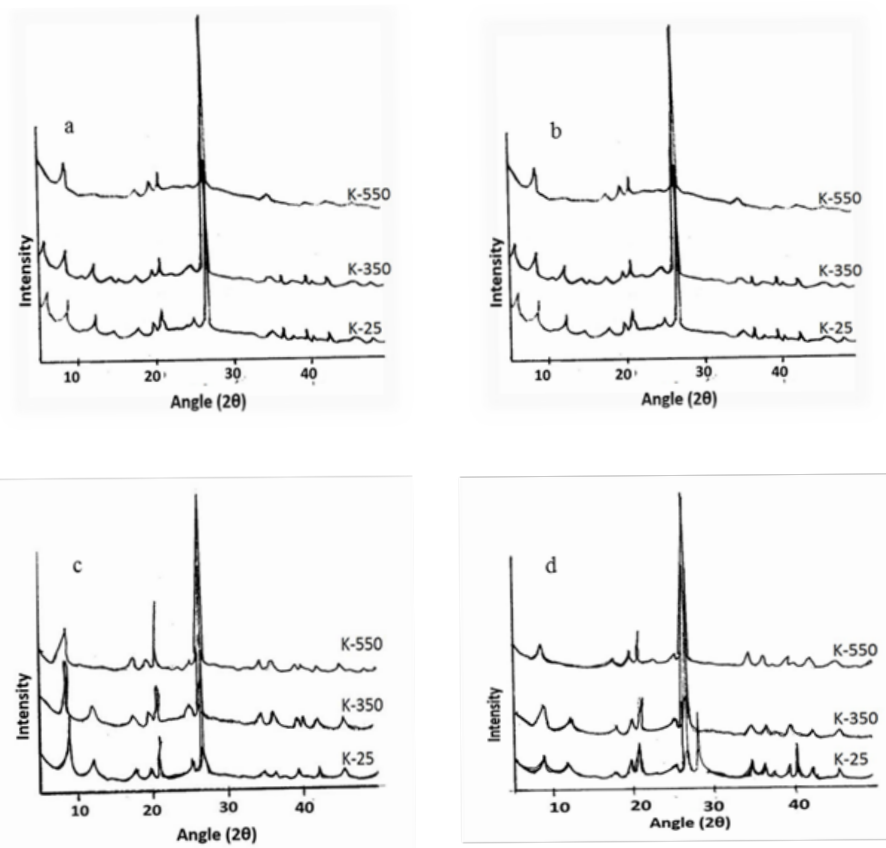

Fig. 6: X-ray diffractograms of K-25, K-350, and K-550 clay fractions of geophagic materials from (a) Tokorme 1, (b) Tokorme 2 (c) Torkorme 3 (d) Wuve.
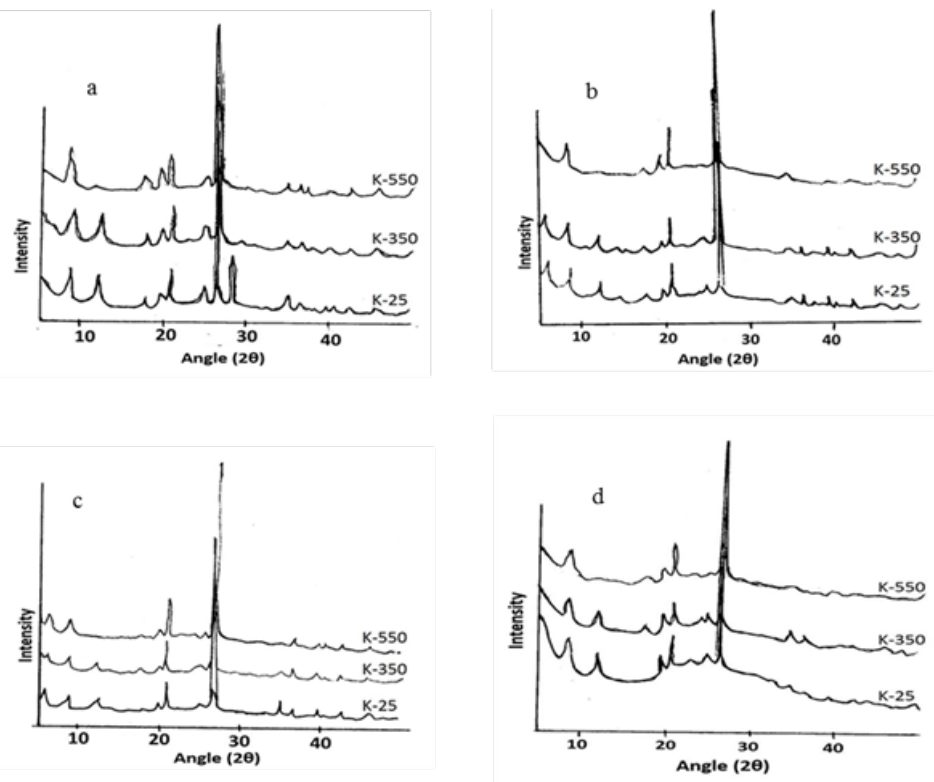

Fig. 7: X-ray diffractograms of K-25, K-350, and K-550 clay fractions of soil from (a) Tokorme 1, (b) Tokorme 2 (c) Torkorme 3 (d) Wuve. 

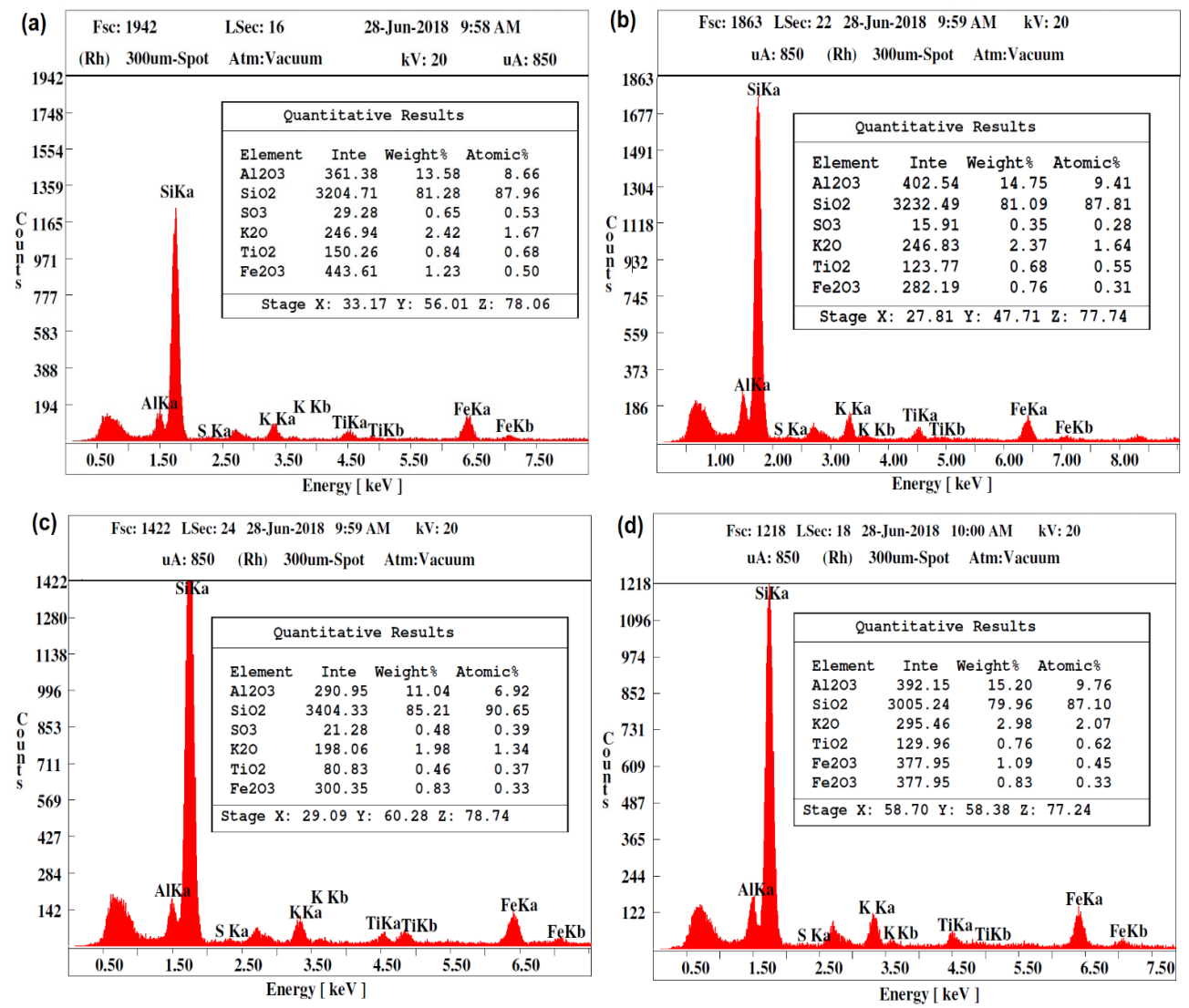

Fig. 8: Major elemental compositions of the geophagic materials; (a) Tokorme 1, (b) Tokorme 2, (c) Tokorme 3, (d) Wuve.

\section{Elemental composition of geophagic materials}

The geophagic materials were dominated by six elements (in oxides) namely $\mathrm{Al}_{2} \mathrm{O}_{3}, \mathrm{SiO}_{2}, \mathrm{SO}_{3}, \mathrm{~K}_{2} \mathrm{O}, \mathrm{TiO}_{2}$ and $\mathrm{Fe}_{2} \mathrm{O}_{3}$ (Fig. 8). Silica $\left(\mathrm{SiO}_{2}\right)$ was the most dominant element in the four geophagic materials. They contained $>79 \%$ $\mathrm{SiO}_{2}$ by weight followed by $\mathrm{Al}_{2} \mathrm{O}_{3} \quad(>11 \%)$ and $\mathrm{K}_{2} \mathrm{O}(>1.98 \%)$. The other elements were present in very small amounts. These results clearly show that the geophagic materials were sialic in composition. 


\section{Discussion}

From petrography, the rock samples were mainly sandstones dominated with quartz and feldspars. The diffractograms also showed the presence of quartz in the soils, rocks and geophagic materials. These results were consistent with the findings of Osae, et al. (2006) who had classified the Buem sandstones as quartz arenite and feldspathic arenite. However, the soils from Tokorme 3 showed relatively high amounts of clay which may be due to appreciable amounts of calcareous and argillaceous materials typically found in the Buem Units (Kesse, 1985). Dickson \& Benneh (1995), also reported that soils from the area were formed from the eroded materials made up mainly of shales and sandstones. The modal composition of the geophagic materials (data not shown) indicates that they contained high amounts of clay ( 88 to $89 \%$ ), moderate amounts of silt and very small amounts of sand. The high clay content of the geophagic materials makes them easily ingestible (Ekosse et al., 2010; Ngole et al., 2010) and less harmful to practitioners (Konta, 1995).

Generally, all the soils showed consistent increase in bulk density with depth. Bulk density typically increases with soil depth due to decreasing levels of organic matter content, less aggregation, and root proliferation and compaction caused by the weight of overlying layers (Tsimba et al., 1999). Soils and horizons with high organic matter content tend to have lower bulk density probably due to higher biological activity which results in the creation of more soil pores (Alexander, 1980). The bulk density of the soils was lower than levels restrictive to root growth (Hunt \& Gilkes, 1992; McKenzie et al., 2004). In general, the soils from Tokorme 2 , Tokorme 3, and Wuve were acid. On the other hand, the soil from Tokorme 1 was neutral to slightly alkaline. The acidic $\mathrm{pH}$ of the soils may be attributed mainly to the mineralogy of the parent materials. The soils were derived from sialic rocks (enriched with silica and alumina), mainly sandstones. Also, the x-ray diffractograms of the soils showed that they contained high amounts of sialic minerals namely quartz, feldspars and muscovite. Abrahams \& Parsons (1997) reported that many geophagic materials are acidic thus imparting a sour taste and making them beneficial during pregnancy because they would prevent excessive secretion of saliva and reduce nausea (Ibeanu et al., 1997). On the other hand, the relatively higher $\mathrm{pH}\left(\mathrm{H}_{2} \mathrm{O}\right)$ of Tokorme 1 could probably be due to that portion of the Bliku hills receiving stronger influence of mafic volcanic materials reported to have influenced the geology of the area (Dapaah-Siakwa \& Gyau-Boakye, 2009). The $\mathrm{pH}\left(\mathrm{CaCl}_{2}\right)$ values of the soil samples and their associated geophagic materials were lower than their $\mathrm{pH}\left(\mathrm{H}_{2} \mathrm{O}\right)$ values. Thus, their $\Delta \mathrm{pH}$ $\left[\mathrm{pH}\left(\mathrm{H}_{2} \mathrm{O}\right)-\mathrm{pH}\left(\mathrm{CaCl}_{2}\right)\right]$ would be negative. The negative $\Delta \mathrm{pH}$ values is an indication that the exchange complex of the soils and geophagic materials would be dominated by negative charges (Tan, 1982).

The soils and their associated geophagic materials were non-saline because their EC values were far lower than the critical value of $2 \mathrm{dS} \mathrm{m}^{-1}$ (Schoeneberger et al., 2012). The low EC levels of the geophagic materials implies that they contained low levels of dissolved salts. Thus, the geophagic materials from Anfoega would show poor flocculation when ingested and may therefore not promote coating of the intestinal mucosa and thus not likely to predispose geophagists to ill-health. The total nitrogen content of the soils and their associated geophagic materials was very small and decreased with decreasing organic carbon content. Organic matter (carbon) is a 
good source of $\mathrm{N}$ from which microbes could synthesize protein (Baddock \& Nelson, 2000; Pierzynski et al, 2000). The organic carbon content of the soils declined sharply with depth. This result was because the soil surfaces served as the repository for litter fall from vegetation and the zone of vigorous microbial activities (Nelson et al. 1994). Generally, low levels of organic carbon in the soils may be mainly due to the generally low biomass generation from the savanna woodland vegetation in the area. The geophagic materials contained very low amounts of organic carbon most probably due to their location, more than $10 \mathrm{~m}$ below the soil surface. The source of the organic $\mathrm{C}$ in the geophagic materials would need further investigation. With low levels of organic carbon, the geophagic materials would be associated with low levels of microbes in the pits. The total and available $\mathrm{P}$ contents of all the soils and geophagic materials were low. Moreover, the amount of total $\mathrm{P}$ in the available form in the soil samples was about $7-27 \%$ whereas in the geophagic materials it was about $10-17 \%$. Thus, the geophagic materials appeared to have fix slightly more $\mathrm{P}$ than the soils. Perhaps, the strong acidic nature of the geophagic materials might have contributed to fixing of more $\mathrm{P}$ and thus reducing its availability (Nartey, 1994).

Apart from the surface and subsurface horizons of the soils that had moderate amounts of exchangeable $\mathrm{Ca}$, there were low levels of exchangeable bases in the soils and geophagic materials. The low levels of the bases in the soils and geophagic materials might probably be due to their paucity in the parent materials and leaching effect. The soils had low to moderate levels of CEC. The geophagic materials, on the other hand, had moderate to high CEC levels. The levels of CEC of the soils and the geophagic materials may be due to a combination of factors including types of clay minerals, amount of clay and organic carbon content (Landon, 1991). The relatively higher CEC of the geophagic materials may be due to the higher amounts of clay they contained.

From their mineralogy, the geophagic materials were dominated by clay minerals. However, they also contained quartz and sericite (altered feldspars). The rocks also contained quartz and relatively small amounts of feldspar and sericite. The presence of these minerals showed that the rocks were sandstones. Kesse (1985) had reported that the Buem formation consists of different types of rocks including greywacke, ferruginous shale, and sandstones. The petrographic examinations showed that the geophagic materials and the rocks were dominated by sialic minerals and were probably of similar provenance.

The $\mathrm{x}$-ray diffractograms of the rock samples show that quartz, feldspar, muscovite and kaolinite were the dominant minerals. Thus, the rocks were sialic in mineralogical composition. This is a further confirmation that the Bliku hills belong to the Buem formation which according to Kesse (1985), are predominantly composed of shales and sandstones. The $\mathrm{x}$-ray diffractograms show that the dominant minerals in the soils included quartz, kaolinite, mica, montmorillonite and muscovite. Thus, the mineralogical composition of the soils was similar to that of the rocks. These results showed that the soils were probably formed residually from the underlying rocks. The high quartz content of the soils probably explains why the soils contained high amount of sand. The collapsed peak at $\mathrm{K}-550^{\circ} \mathrm{C}(12.28 \AA)$ confirmed the presence of kaolinite in the soils. The $\mathrm{x}$-ray diffractograms of the geophagic materials show that they were also dominated with quartz, kaolinite, 
mica, feldspar and muscovite. In the geophagic materials too, the collapse of the peak 12.28 $\AA$ at $\mathrm{K}-550^{\circ} \mathrm{C}$ confirmed the presence of kaolinite. The elemental composition of the geophagic materials also show that they were dominated by $\mathrm{SiO}_{2}$ and $\mathrm{Al}_{2} \mathrm{O}_{3}$ which confirms that they were sialic. The low $\mathrm{pH}$ values and the presence of sialic minerals suggest that the geophagic materials and the overlying rocks (sandstones) were of the same provenance, the Buem formation.

\section{Conclusions}

Except for Tokorme 2 which contained high amounts of clay, the soils were generally sandy probably due to the influence of underlying sandstones. The geophagic materials contained relatively higher amounts of clay than the soils. While the $\mathrm{pH}$ of the soil from Tokorme 1 was neutral to slightly alkaline, probably due to relatively stronger influence of mafic volcanic materials, that of the other soils ranged from slightly acid to strongly acid. The $\mathrm{pH}$ of the geophagic materials was strongly acid. The geophagic materials had higher CEC than the soils perhaps due their higher clay content. The thin section petrography of the rocks and the geophagic materials showed they were composed of similar minerals namely quartz, feldspars and sericite or clay. However, they contained different proportions of the minerals; whereas the rocks were dominated by quartz, the geophagic materials where enriched with clay. It would therefore be apt to describe the geophagic materials from Anfoega as sialic shales with kaolinite as one of the minerals. The x-ray diffractograms also show that the rocks, soils and geophagic materials contained similar sialic minerals which were mainly quartz, muscovite, feldspars, and kaolinite. Elemental analysis also shows that the geophagic materials were dominated by $\mathrm{SiO}_{2}$ and $\mathrm{Al}_{2} \mathrm{O}_{3}$. The similarities in the mineralogical compositions of the geophagic materials and the rocks confirm that they were of similar provenance, the Buem formation. To elucidate the origin of the geophagic materials, the relationship between their mineralogy and that of the overlying sandstones needs to be comprehensively investigated. Probably, the sialic minerals in the geophagic materials were leached from the overlying sandstone. The results also indicate that the soils were formed residually from the underlying sandstones.

\section{Acknowledgements}

We are very grateful to Mr. Benard Anipa, former Chief Technician of the Department of Soil Science, University of Ghana for assisting in the fieldwork. The authors thank Prof. Juana Dolores Jordá Guijarro, Multidisciplinary Institute for Environmental Studies, University of Alicante, Spain for the XRF-elemental analysis of the geophagic materials.

\section{References}

Abass, K. (2004) A Regional Geography of Ghana. Delcam Publications, Accra, Ghana.

Abrahams, P. W. (2002) Soils: their implications to human health. Science of Total Environment 291, 1 - 32.

Abrahams, P. W. (2005) Geophagy and the involuntary ingestion of soil: Essentials of Medical Geology 435 - 455.

Abrahams, P. W. \& Parsons J. A. (1996) Geophagy in the Tropics: A literature review in Geographical Journal 162 (1).

Abrahams, P. W. \& Parsons J. A. (1997) Geophagy in the Tropics: An appraisal of three geophagical materials. Environmental Geochemistry and Health. 19, 19 - 22.

Affaton, P., Aguirre, L. \& Menot, R. P. (1997) Thermal and geodynamic setting of the Buem volcanic rocks near Tie'le', Northwest Benin, 
West Africa. Precambrian Research 82, 191 209.

Agyei Duodu, J., Loh, G. K., Boamah, K. O., Baba, M., Hirdes, W., ToloczyKi, M. \& Davis, D. W. (2009) Geological Map of Ghana 1:1 000 000. Geological Survey Department of Ghana.

Alexander, M. (1980) Effect of acidity on microorganisms and microbial processes in soils. In: Hutchinson, J. C. and Havas, M. eds. Effect of acid precipitation on terrestrial ecosystem. Plenum, New York. 303 - 38.

Baddock, J. A. \& Nelson, P. N. (2000) Soil organic matter. CRC Press.

Blake, G. R. (1965) Bulk density. In: Methods of Soil Analysis. Black, C.A. ed. American Society of Agronomy, Madison, Wisconsin, pp. 374-390.

Brady N. C. \& WeIl R. R. (1999) The nature and properties of soil. 12th ed. Prentice Hall, New Jersey, USA. p.852

Brand, C. E., De Jager, L. \& Ekosse, G. (2009) Possible health effects associated with human geophagic practice: an overview. Medical Technology SA 23, 11 - 13.

Bray, R. H. \& Kurtz, L. T. (1945) Determination of total, organic, and available forms of phosphorus in soils. Soil Science 59, 39 - 45.

Callahan, K. L. (2000) Pica, geophagy, and rock art: ingestion of rock powder and clay by humans and its implication for the production of some rock art on a global basis. A paper read at the Philadelphia SAA conference in April 8, 2000; Available:http://www.geocities.com/Anthens/ Acropolis/5579/pica.html.

Clark, J. D. (2001) Kalambo falls prehistoric Site: Volume III. Cambridge (UK): Cambridge University Press.

DANFord, D. E. (1982) Pica and Nutrition. Annual Review of Nutrition 2, 205 - 320.

Dapaah-Siakwa, S. \& Gyau-Boakye, P. (2009) Hydrogeologic frame and borehole yields in Ghana. Hydrogeology Journal 8, 408 - 416.
DAY, P. E. (1965) Particle fractionation and particle size analysis. In: Methods of Soil Analysis. Black, C.A. ed. American Society of Agronomy, Madison, Wisconsin, pp. 545 - 567.

Dickson, K. B. \& Benneh, G. (1995) A new geography of Ghana. Revised Edition. Longman, UK, $170 \mathrm{pp}$.

Ekosse, G. I. E., De Jager, L. \& Ngole, V. M. (2010) Traditional mining and mineralogy of geophagic clays from Limpopo and Free State Provinces, South Africa. African Journal of Biotechnology 9, 8058 - 8067.

FAO (2006) Guidelines for soil description. Food and Agriculture Organization of the United Nations. $4^{\text {th }}$ edition, p. 44-59. Rome.

Ferrell, R. E. (2008) Medicinal clay and spiritual healing. Clays and Clay Minerals 56, 751 760 .

Geissler, P. W., Mwaniki, D. L., Thiongo, F. \& Fris, H. (1998) Geophagy as a risk factor for Geohelminth infections: a longitudinal study of Kenyan primary school children Transactions of the Royal Society of Tropical Medicine and Hygiene 92, 7 - 11.

GHANA STATISTICAL SERVICE, (2010) Population and Housing Census: District Analytical Report North Dayi, pp 2 - 39.

GHORBANI, H. (2008) Geophagia, a soil - environmental related disease. International meeting on Soil Fertility Land Management and Agroclimatology. Turkey 957 - 967.

GonyeA, J. (2007) PicA: do you know what your patients are eating? Nephrol Nurs J. 34, 230 231.

Gosselain, O. P. (1999) In pots we trust: The processing of clays and symbols in sub-Saharan $A f$ rica Journal of Material Culture 4, 205-230.

Halsted, J. A. (1968) Geophagia in man. Its nature and nutritional effects. American Journal Clinical Nutrition 21. 
Harvey, P. W. J., Dexter, P. B. \& Darton-Hill, I. (2000) The impact of consuming iron from non-food sources on iron status in developing countries. Journal of Public Health, and Nutrition 3, $375-383$.

Hesse, P. R. (1971) A textbook of soil chemical analysis. John Murray (Publisher) Ltd., London, U.K.

Hooda, P. S., Henry C. J. K., Seyoum, T. A., ArmStrong, L. D. M. \& Fowler M. B. (2004) The potential impact of soil ingestion on human mineral nutrition. Science of the Total Environment 333, $75-87$.

Hunt, N. \& Gilkes R. (1992) Farm Monitoring Handbook. The University of Western Australia: Nedlands, WA.

Hunter, J. M. (1973) Geophagy in Africa and in the United States: a culture-nutrition hypothesis. Geographical Review 63, 170 - 195.

Hunter, J. M. (1993) Macroterm geophagy and pregnancy clays in Southern Africa. Journal of Cultural Geography 14, 69 - 92.

Hunter, J. M. \& De Kleine, R. (1984) Geophagy in Central America. Geographical Review 74, $157-169$.

Hunter, J. M., Horst, O. H. \& Thomas, R. N. (1989) Religious Geophagy as a Cottage Industry: The Holy Clay Tablet of Esquipulas, Guatemala. National Geographic Research 5, 281 $-295$.

Ibeanu, G. E. L., Dim, L. A., Mallam, S. P., AkPa, T. C. \& MunYithya, J. (1997) Nondestructive XRF analysis of Nigerian and Kenyan clays. Journal of Radioanalytical and Nucleic Chemistry 221, 207 - 209.

Izugbara, C. O. \& Emmanuel, C. J. (2003) The cultural context of geophagy among pregnant and lactating Ngwa women of Southeastern Nigeria. The African Anthropologist, 2 (2).

JoNES, W. (1990) The Buem volcanic and associated sedimentary rocks, Ghana: a field and geo- chemical investigation. Journal of African Earth Sciences 11 (3-4), 373 - 383.

Kesse, G. O. (1985) The mineral and rock resources of Ghana. A. A. Balkema, Roterdam. Precambrian Research 46, 139 - 165.

KonTA, J. (1995) Clay and man: clay raw materials in the service of man. Applied Clay Science 10, $275-335$.

Krishnamani, R. \& Mahaney, W. C. (2002) Geophagy among primates: adaptive significance and ecological consequences. Animal Behaviour 59, $899-915$.

Landa, E. \& Feller, C. (2009) Soil and Culture. Springer Publishers, Netherlands, p370.

Landon, J. R. (1991) Booker Tropical Soil Manual. A Handbook for soil survey and agriculture land evaluation in the tropics and subtropics. Landon, J. R. ed. Booker Tate, Thame, Oxon, UK, pp. $58-125$.

LAufer, B. (1930) Geophagy. Field Museum of Natural History - Anthropological Series 18, 97 $-198$

Mahaney, W. C. \& Krishnamani, R. (2003) Understanding geophagy in animals; Standard procedure for sampling soils. Journal of Chemical Ecology 29 (7), 1503 - 1523.

Mahaney, W.c., Milner, M. W., Mulyono, H. S., Hancock, R. G. V., Aufreiter, S., Reich, M. \& WINK, M. (2000) Mineral and chemical analyses of soils eaten by humans in Indonesia. International Journal of Environmental Health 10, 93 - 109.

MckenZie, N. J., JACQuier D. J., IsBell R. F. \& Brown K. L. (2004) Australian Soils and Landscapes an Illustrated Compendium. CSIRO Publishing: Collingwood, Victoria.

MehrA, O. P., \& JACKSON, M. L. (1960) Iron oxide removal from soils and clays by dithionite-citrate system buffered with sodium bicarbonate. In Clays Clay Miner. Proc. $7^{\text {th }}$ Conf., $\mathrm{p}$ 317 - 327, Pergamon Press, London. 
Moore, D. F. J. \& Sears, D. A. (1994) Pica, iron deficiency and the medical history. The American Journal of Medicine 97, 390 - 393.

Nartey, E. (1994) Pedogenic changes and phosphorus availability in some soils of the Northern Ghana. M.Phil theses, pp 88 - 94.

Nelson, P. N., Dictor, M. C. \& Soula. S. (1994). Availability of organic carbon in soluble and particle size fractions from a soil profile. Soil Biol. Biochem. 26, 1549 - 1555.

Ngole, V. M., Ekosse, G. E., De Jager, L. \& Songca, S. P. (2010) Physicochemical characteristics of geophagic clayey soils from South Africa and Swaziland. African Journal of Biotechnology 9, 5929 - 5937.

Nude, P. M., Kwayisi, D., Taki, N. A., Kutu, J. M., Anani, C., Banoeng-Yakubo, B, \& Asiedu, D. K. (2015) Petrography and chemical evidence for multi-stage emplacement of western Buem volcanic rocks in the Dahomeyide orogenic belt, southeastern Ghana, West Africa. Journal of African Earth Science 112, 314 327.

Olsen, S. R., Cole, C. V., Watanabe, F. S. \& Dean, L. A. (1954) Estimation of available phosphorus in soils by extraction with sodium bicarbonate. USDA Department circular 939.

Osae, S., Asiedu, D. K., Benoeng-Yakubo, B., KoeBerl, C., Dampare, S. B., (2006) Provenance and tectonic setting of the Late Proterozoic Buem sandstones of southeastern Ghana: evidence from Geochemistry and detrital modes. Journal of African Earth Sciences 44, 85 - 96.

Oyama, M. \& Takehara, H. (1970) Revised Standard Soil Colour Charts. 2 ${ }^{\text {nd }}$ Edition. Research Council for Agriculture, Forestry and Fisheries, Ministry of Agriculture and Forestry, Tokyo, Japan.

Pierzynski, G. M., Sims, J. T. \& Vance, G. F. (2000) Soil phosphorus and Environmental quality. In soils and environmental quality, pp. 155 - 207, CRC press, Boca Raton.
Reilly, C. \& Henry, J. (2000) Geophagia: why do humans consume soil? Nutrition Bulletin 25 (2), $141-144$.

Root-Bernstein, R. \& Root-Bernstein, M. (2000) Honey, mud, maggots and other medical marvels: the science behind folk remedies and old wives tales. London: Pan Books (280 pp).

Rose, E., Porcerelli, J. \& Neale, A. (2000) 'Pica: Common but commonly missed". Journal Chemical Ecology 29 (7), 1525 - 1547.

Schoeneberger, P. J., Wysocki, D. A., Benham, E. C. \& Soll Survey Staff (2012) Field book for describing and sampling soils, Version 3.0. p. 2-89. Natural Resources Conservation Service, National Soil Survey Center, Lincoln, NE.

Schulze, D. G. (2005) Encyclopedia of Soils in the Environment, Elsevier / Academic Press, Boston, in D. Hillel (editor-in-chief), Clay Minerals 1, 246 - 254.

Siewe, C. N. \& Diko, M. L. (2000) Geophagia among female adolescents as a culturally driven Practice University of Limpopo, South Africa.

SOIL RESEARCH INSTITUTE (1999) Soil Map of Ghana, FAO/ UNESCO, 1990. Land suitability section, Soil Research Institute Ghana.

Starks, P. T. B. \& Slabach, B. L. (2012) The Scoop on eating dirt. Scientific American, 00368733 , 306(6). Available from: http://web.ebsocohost.com.

STIEGLeR, L. (2005) Understanding pica behavior: a review for clinical and educational professionals. Focus Autism Other Dev Disabil 20, $27-38$.

Tan, K. H. (1982) Principles of Soil Chemistry. Marcel Dekker Inc., Madison, New York, U.S.A. p. 521.

Tano-Debrah, K. \& Bruce-Baiden, G. (2010) Microbiological characterization of dry white clay, a pica element in Ghana, http://www.sciencepub.net/report. 
TAYIE, F. (2004) Pica. Motivating factors and health Issues. African Journal of food Agriculture, Nutrition and Development 4, (1).

Tayie, F. A., Koduah, G. \& Mork, S. A. P. (2013) Geophagia clay soil as a source of mineral nutrients and toxicants. African Journal of food Agriculture, Nutrition and Development 13 (1), 7157 - 7170

Tsimba, R., Hussein, J. \& Ndlovu, L. R. (1999) Relationships between depth of tillage and soil physical characteristics of sites farmed by smallholders in Mutoko and Chinyika in Zimbabwe. Published in: Kaumbutho P. G, Simalenga T. E (1999). Conservation tillage with animal traction. A resource book of the Animal Traction Network for Eastern and Southern Africa (ATNESA). Harare. Zimbabwe. p. 173.

UNIMAX MACMILLAN (2001) Senior secondary atlas. Nabila, J.S. and Kofie, R. (eds.). Accra, Ghana.

UtARA, S. (2002) Chemical analyses of pica soil eaten by villagers in Sisaket Province. MSc Unpublished. Thesis. Suranaree University of Technology, Thailand. pp 9-10.

Vermeer, D. E. (1966) Geophagy among the Tiv of Nigeria. Annals of the Association of American Geographers 56, 197 - 204.

Vermeer, D. E. (1971) Geophagy among the ewe of Ghana. Ethnology 10, $56-72$.

Vermeer, D. E. (1987) Geophagy in Africa, Bull. Sbreveport Med. Soc. 38, 13 - 14.
Vermeer, D. E. \& Frate, D. (1979) Geophagia in rural Mississippi: environmental and cultural contexts and nutritional implications. American Journal Clinical Nutrition 32, 2122 - 2135.

Walkley, A. \& Black, I. A. (1934) An examination of the Degtjareff method for determining soil organic matter and a proposed modification of the chromic acid titration method. Soil Science 37, $29-38$.

WiLson, M. J. (2003) Clay mineralogical and related characteristics of geophagic materials. Journal of Chemical Ecology 29, 1525 - 1547.

Wong, M. S., Bundy, D. A. \& Golden, M. H. (1991) The rate of ingestion of Ascaris lumbricoides and Trichuris trichiura eggs in soil and its relationship to infection in two children homes in Jamaica. Transactions of the Royal Society of Tropical Medicine and Hygiene 85, 89 - 91.

Woywodt, A. \& Kiss, A. (2002) Geophagia: the history of earth-eating. Journal of the Royal Society of Medicine 95, 143 - 146.

Young, S. L., Wilson, M. J., Miller, D. \& Hillier, S. (2008) Toward a comprehensive approach to the collection and analysis of pica substances, with emphasis on geophagic materials. PLoS ONE 3: e3147. doi; 10, 137/journal. pone.0003147.

Young, S. L., Wilson, M. J., Hillier, S., Delbos, E., Ali, S. M. \& Stoltzfus, J. R. (2010) Differences and commonalities in Physical, Chemical and Mineralogical Properties of Zanzibari Geophagic Soils. Journal Chemical Ecology 36, 129 - 140.

ZIEGLER, J. L. (1997) Geophagy: A vestige of paleonutrition? Tropical Medicine International. Health 2 (7), 609 - 611.

Received 03 May 20; revised 16 Mar 21. 